\title{
Face Recognition using Texture Features Extracted form Haarlet Pyramid
}

\author{
Dr.H.B.Kekre \\ Senior Professor \\ Computer Engineering Department, \\ MPSTME, NMIMS (Deemed-to-be \\ University), Mumbai, India
}

\author{
Sudeep D. Thepade \\ Ph.D.Research Scholar \& Associate \\ Professor \\ Computer Engineering Department, \\ MPSTME, NMIMS (Deemed-to-be \\ University), Mumbai, India
}

\author{
AkshayMaloo \\ Computer Engineering Department, \\ MPSTME, NMIMS (Deemed-to-be \\ University), Mumbai, India
}

\begin{abstract}
Face recognition has been a fast growing, challenging and interesting area in real-time applications. A large number of face recognition algorithms have been developed for decades. The paper presents novel Haatlet Pyramid based face recognition technique. Here face recognition is done using the image feature set extracted from Haarlets applied on the image at various levels of decomposition. Here the image features are extracted by applying Haarlets on gray plane (average of red, green and blue. The proposed technique is tested on two image databases having 100 images each.

The results show that Haarlets level-3 and Haarlets level-4 outperforms other Haarlets, because the higher level Haarlets are giving very coarse texture features while the lower level Haarlets are representing very fine texture features which are less useful to differentiate images in face recognition..
\end{abstract}

\section{Keywords}

Face recognition, Haarlet Pyramid,Haarlet Levels

\section{INTRODUCTION}

The term face recognition refers to identifying, by computational algorithms, an unknown face image. This operation can be done by means of comparisons between the unknown face and faces stored in a database.

In the area of human computer interaction, an ultimate goal is for machine to understand, communicate with and react to humans in natural ways. Although there are many other avenues to person identification - gait, clothing, hair, voice, and height are all useful indication of identity of the person, none are as compelling as face recognition.

Face recognition systems have a wide range of applications, especially when dealing with security applications, like computer and physical access control, real-time subject identification and authentication, and criminal screening and surveillance.

Biometrical identification based on iris, fingerprint and other attributes all suffer from a series of drawbacks, including need of high precision image acquisition equipment, difficulty to use with video images and need of agreement when doing the image acquisition. Systems that use face recognition don't have any of these restrictions.
Face recognition is a difficult task, because it cannot be performed by pixel to pixel comparison of two images. Some aspects of the face image must be irrelevant when doing the recognition, like illumination, pose, position, scale, environment, accessories and small age differences. So, face recognition systems require use of accurate and robust methods. Principal component Analysis is usually used because of its acceptable performance, but it is very time consuming.

\section{HAAR TRANSFORM}

This sequence was proposed in 1909 by AlfrédHaar [13]. Haar used these functions to give an example of a countable orthonormal system for the space of square-integral functions on the real line. The study of wavelets, and even the term "wavelet", did not come until much later [14]. The Haar wavelet is also the simplest possible wavelet. The technical disadvantage of the Haar wavelet is that it is not continuous, and therefore not differentiable. This property can, however, be an advantage for the analysis of signals with sudden transitions, such as monitoring of tool failure in machines.

The Haar wavelet's mother wavelet function $\psi(\mathrm{t})$ can be described as:

$$
\psi(t)=\left\{\begin{array}{r}
1,0 \leq t<\frac{1}{2} \\
-1, \frac{1}{2} \leq t<1 \\
0, \text { otherwise }
\end{array}\right.
$$

and its scaling function $\varphi(t)$ can be described as:

$$
\varphi(t)=\left\{\begin{array}{l}
1,0 \leq t<1 \\
0, \text { otherwise }
\end{array}\right.
$$

\section{HAARLETS}

The procedure of generating Haarlets $[2,12]$ is shown in flowchart given in figure 1 and can be explained as given in following steps. Let $\mathrm{I}_{\mathrm{NXN}}$ be the image with size NxN of which Haarlets are to be obtained and $\mathrm{H}_{\mathrm{NxN}}$ be the Haar transform matrix of size $\mathrm{NxN}$.

a. Apply Haar transform of size $\mathrm{NxN}$ on the image of size $\mathrm{NxN}$ to get Haar transformed image with approximation (hIA), horizontal (hIH), vertical (hIV) and diagonal (hID) components. 


$$
\begin{aligned}
\mathrm{hI}_{\mathrm{NxN}} & =[\mathrm{hIA}, \mathrm{hIH}, \mathrm{hIV}, \mathrm{hID}] \\
& =\left[\mathrm{H}_{\mathrm{NxN}}\right]\left[\mathrm{I}_{\mathrm{NxN}}\right]\left[\mathrm{H}^{\prime}{ }_{\mathrm{NxN}}\right]
\end{aligned}
$$

b. Replace horizontal (hIH), vertical (hIV) and diagonal (hID) components with zero to get modified Haar transformed image 'hwI'.

$$
\text { hwI } \mathrm{I}_{\mathrm{NxN}}=[\mathrm{hIA}, \text { Zero, Zero, Zero }]
$$

c. Apply inverse Haar transform on the modified Haar transformed image to get h'wI.

$h^{\prime} \mathrm{II}_{\mathrm{NxN}}=\left[\mathrm{H}^{\prime}{ }_{\mathrm{NxN}}\right]\left[\mathrm{hwI} \mathrm{I}_{\mathrm{NxN}}\right]\left[\mathrm{H}_{\mathrm{NxN}}\right]$

d. Down-sample the result of step'c' (h'wI) by taking alternate rows and columns to get image with size $\mathrm{N} / 2 \mathrm{xN} / 2$.

$\operatorname{dhI}_{\mathrm{N} / 2 \times \mathrm{N} / 2}=$ downsample( h'wI $\left.\mathrm{NxN}\right)$

e. Apply Haar transform of size $\mathrm{N} / 2 \mathrm{xN} / 2$ on down-sampled image $\left(\mathrm{dwI}_{\mathrm{N} / 2 \times \mathrm{N} / 2}\right)$ to get the Haarlet of level-1.

Haarlet Level I =

$\left[\mathrm{H}_{\mathrm{N} / 2 \times \mathrm{N} / 2}\right]\left[\mathrm{dwI}_{\mathrm{N} / 2 \times \mathrm{N} / 2}\right]\left[\mathrm{H}^{\prime}{ }_{\mathrm{N} / 2 \times \mathrm{N} / 2}\right]$

f. Repeat steps b to e 'P-1' times on the level 1Haarlet to get Haarlet of level ' $P$ '.

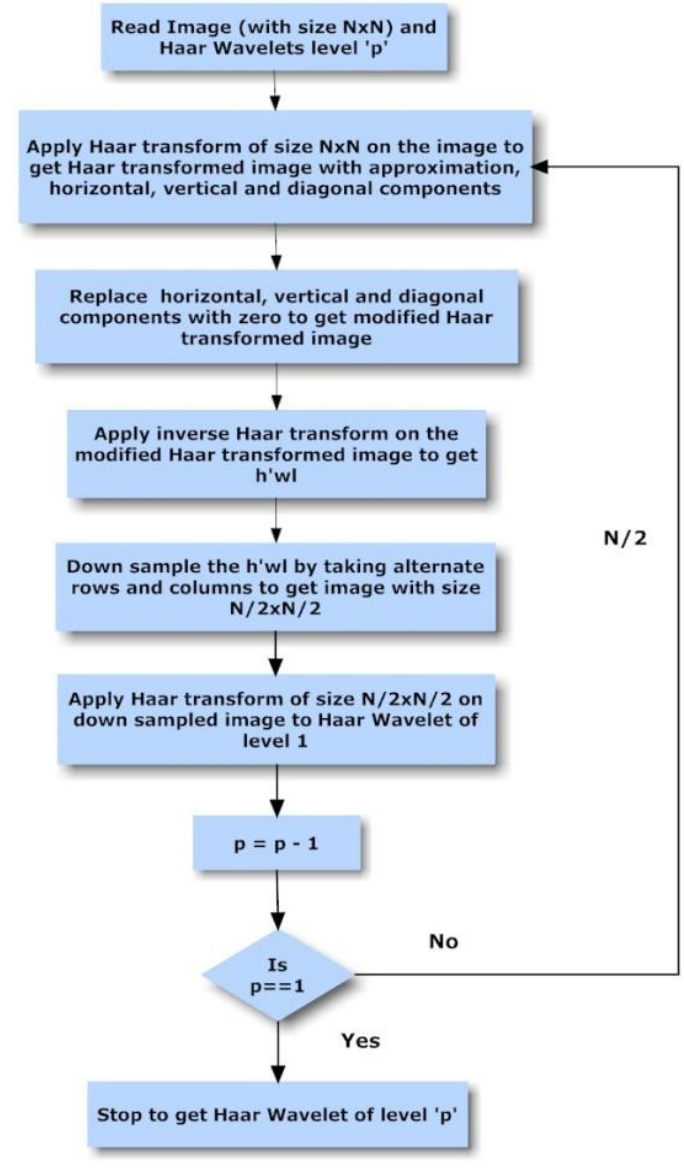

Fig. 1Flowchart for generating Haarlets of level 'p'

\section{HAARLETS PYRAMID}

The Haarlets of a particular image for different levels, when considered together gives Haarlet Pyramid [2]. Here for generating first level of Haarlet pyramid Haar transform is applied on image to get approximation, horizontal, vertical and diagonal components. The approximate components of first level Haarlet are considered to be transformed with Haar $\mathrm{T}$ to get second level Haarlet. The Haarletpyramid of sample images are shown in figure 2 given below. Here the face image is decomposed into two levels of Haarlet pyramid as Haarlet level-1, Haarlet level-2.

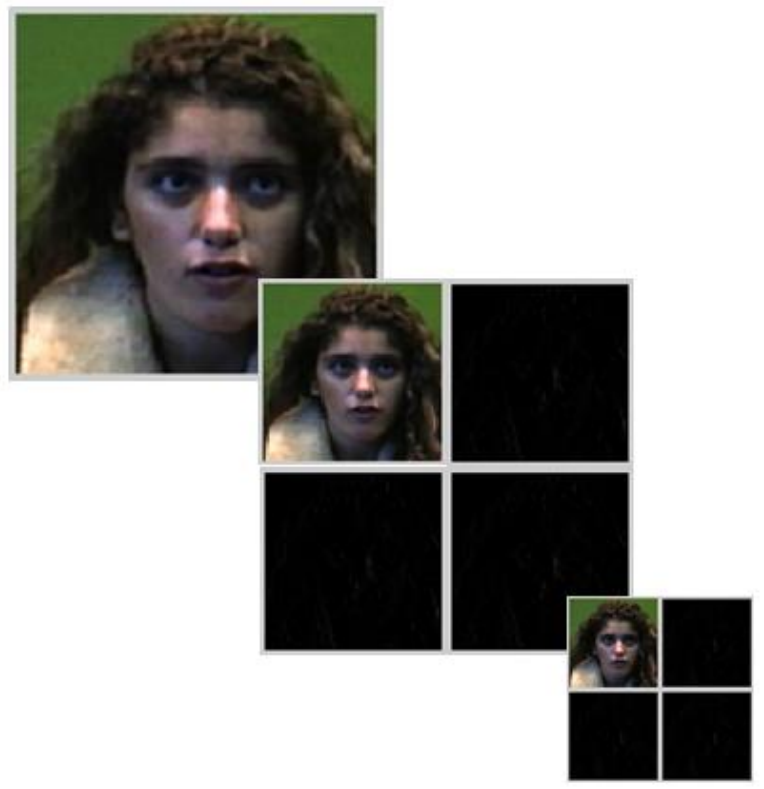

Fig. 2 Different Levels of Haarlet Pyramid

\section{EUCLIDEAN DISTANCE}

We have used Euclidean distance [3-9] on the feature set as the similarity measure. The Direct Euclidian Distance between training image $\mathrm{P}$ and test image $\mathrm{Q}$ can be given as equation 1 , where Vpi and Vqibe the feature vectors of training image $\mathrm{P}$ and test image $Q$ respectively of size ' $n$ '.

$$
E D=\sqrt{\sum_{i=1}^{n}(V p i-V q i)^{2}}
$$

\section{PROPOSED TECHNIQUES [15]}

\subsection{Feature Extraction}

Here the approximate components of Haarlet level-1, Haarlet level-2,...,Haarlet level-7 are obtained for every image in the database and haar transforms of respective sizes are applied on them, the results are stored as feature vectors for respective image. At level-1 Haarlet the feature vector size is $\mathrm{N} / 2 \mathrm{xN} / 2$. At level-2 Haarlet the feature vector size is $\mathrm{N} / 4 \mathrm{xN} / 4$ and so on. Thus the feature vectors for upto level-7 Haarlets are extracted and the feature vector database is generated.

\subsection{Query Execution}

Here the feature set of Haarlet level-p is extracted as a feature set for query image using proposed technique of Haarlet generation. 
Then these are matched with Haarlet level-p feature vector database using Euclidian distance as similarity measure. As compared to applying complete Haar $\mathrm{T}$ on the image, this proposed method takes fewer computations to extract the feature set and gives better precision and recall values.

For image of size $\mathrm{NxN}$ complete Haar needs $2 \mathrm{~N}^{2} \log _{2}(\mathrm{~N})$ additions and for Haarlet of level-p the number of additions needed are $2\left(\mathrm{~N} / 2^{\mathrm{p}}\right)^{2} \log \left(\mathrm{N} / 2^{\mathrm{p}}\right)$ as the size of feature vector would be $\left(\mathrm{N} / 2^{\mathrm{p}}\right) \mathrm{x}\left(\mathrm{N} / 2^{\mathrm{p}}\right)$. This gives tremendous reduction in query execution time using higher Haarlet level.

\section{IMPLEMENTATION}

\subsection{Platform}

The experiments were performed on Matlab R2009b, Intel Core 2 Duo T8100 (2.1 Ghz).

\subsection{Databases}

The experiments were performed on two databases:

\subsubsection{Face Database [1]:}

Created by Dr Libor Spacek this database has 100 images (each with 180 pixels by 200 pixels), corresponding to 20 persons in five poses each, including both males and females. All the images are taken against a dark or bright homogeneous background, little variation of illumination, different facial expressions and details. The subjects sit at fixed distance from the camera and are asked to speak, whilst a sequence of images is taken. The speech is used to introduce facial expression variation. The images were taken in a single session. The five poses of Face database are shown in Figure 3.

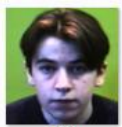

(66)

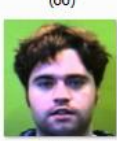

(76)

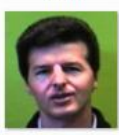

(86)

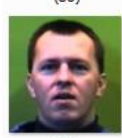

(96)

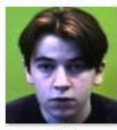

(67)

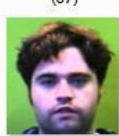

(77)

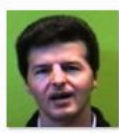

(87)

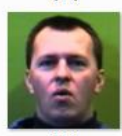

(97)

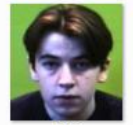

(68)

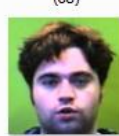

(78)

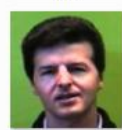

(88)

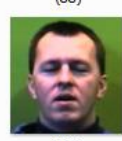

(98)

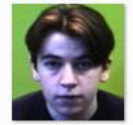

(69)

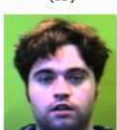

(79)

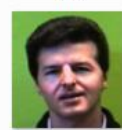

(89)

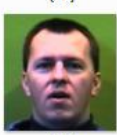

(99)

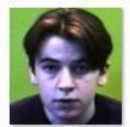

(70)

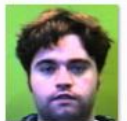

(80)

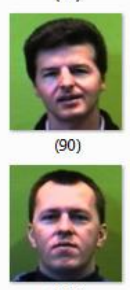

(100)
Fig. 3 Sample Images from Face Database

\subsubsection{Our Own Database:}

This database has 100 images (each with 128 pixels by 128 pixels), corresponding to 20 persons in five poses each, including both males and females. All the images are taken against a dark or bright homogeneous background, with variation of illumination, highly different facial expressions and details (open/closed eyes, smiling/non smiling, glasses/no glasses).

Our database has many variations in intensity, the image sizes are varying and it is non-controlled, this was done to test the ruggedness of our algorithm used for face recognition. The five poses of our database are shown in Figure 4.
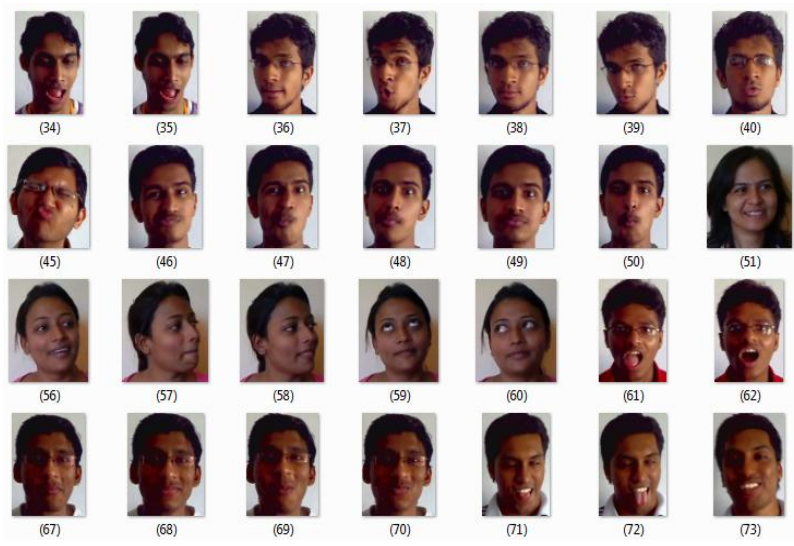

Fig. 4 Sample Images from Our Own Database

\section{RESULTS \& DISCUSSIONS}

The false acceptance rate (FAR) [11] is the measure of the likelihood that the biometric security system will incorrectly accept an access attempt by an unauthorized user. A system's FAR typically is stated as the ratio of the number of false acceptances divided by the number of identification attempts.

The false rejection rate (FRR) [10] is the measure of the likelihood that the biometric security system will incorrectly reject an access attempt by an authorized user. A system's FRR typically is stated as the ratio of the number of false rejections divided by the number of identification attempts.

During performance testing a test image was considered and five closest matches were displayed, so percentage correct detection is the percentage of relevant images it returned and percentage incorrect detection is the amount irrelevant images it returned.

\subsection{Face Database}

In all 100 queries were tested on Face database for analysing the performance of proposed face recognition techniques. Fig 5 gives the percentage of FAR and FRR for face recognition using variations in Haarlet based techniques. Here it is observed that all Haarlet levels except Haarlet-level-7 give the same performance but the advantage of using higher level Haarlets is reduced feature vector size which gives faster recognition as lower numbers of coefficients are used for comparison.

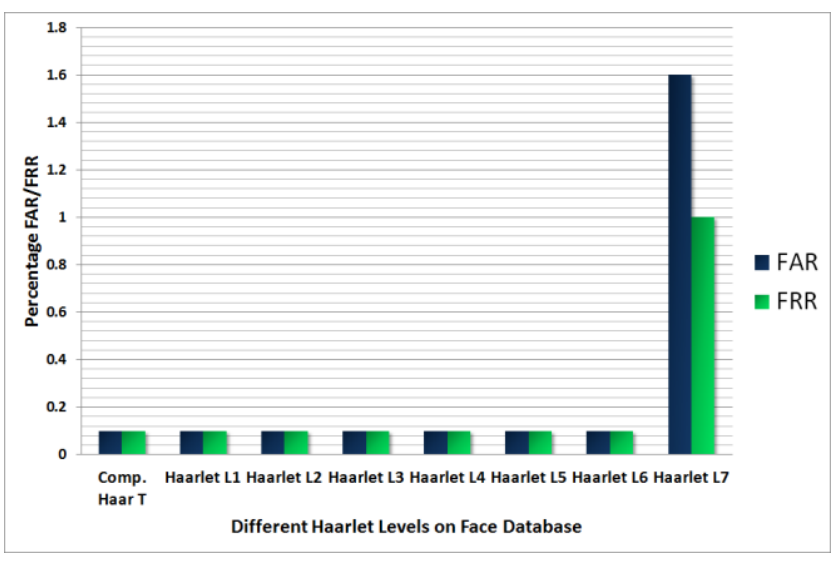

Fig. 5 FAR/FRR Using Haarlets on Face database 


\subsection{Own Database}

In all 100 queries were tested on Our Own database for analysing the performance of proposed face recognition techniques. Fig 6 gives the percentage of FAR and FRR for face recognition using variations in Haarlet based techniques. Here it is observed that Haarlet-level-3 and Haarlet-level-4 give the best performance. It outperforms complete Haar transform and because of reduced feature vector size gives faster recognition.

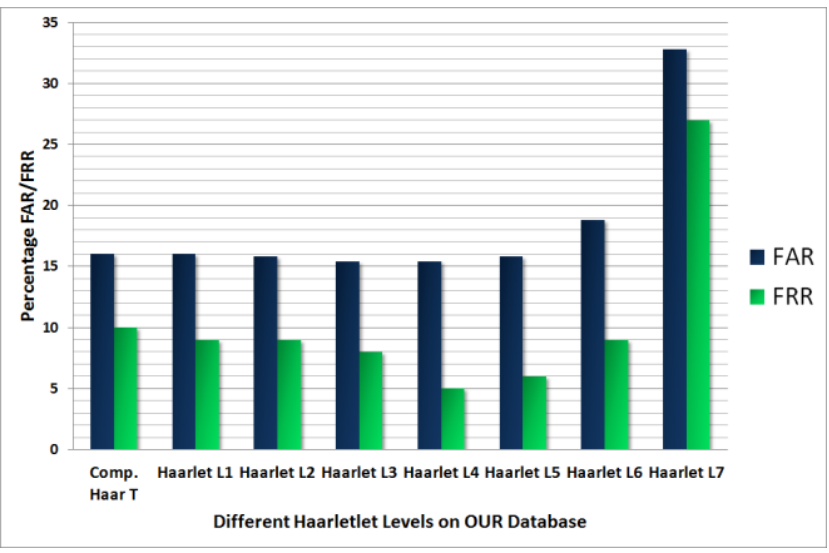

Fig. 6 FAR/FRR FAR/FRR Using Haarlets on Our database

Table 1.Correct/Incorrect Detection Using HaarletsOn Face Database

\begin{tabular}{|l|c|c|}
\hline Partial coefficients & $\begin{array}{l}\text { Percentage } \\
\text { Correct } \\
\text { Detection }\end{array}$ & $\begin{array}{l}\text { Percentage } \\
\text { Incorrect } \\
\text { Detection }\end{array}$ \\
\hline Comp. Haar T & $99.9 \%$ & $0.1 \%$ \\
\hline Haarlet Level 1 & $99.9 \%$ & $0.1 \%$ \\
\hline Haarlet Level 2 & $99.9 \%$ & $0.1 \%$ \\
\hline Haarlet Level 3 & $99.9 \%$ & $0.1 \%$ \\
\hline Haarlet Level 4 & $99.9 \%$ & $0.1 \%$ \\
\hline Haarlet Level 5 & $99.9 \%$ & $0.1 \%$ \\
\hline Haarlet Level 6 & $99.9 \%$ & $0.1 \%$ \\
\hline Haarlet Level 7 & $98.4 \%$ & $1.6 \%$ \\
\hline
\end{tabular}

Table 2. Correct/Incorrect Detection Using HaarletsOn Our Database

\begin{tabular}{|l|c|c|}
\hline Partial coefficients & $\begin{array}{l}\text { Percentage } \\
\text { Correct } \\
\text { Detection }\end{array}$ & $\begin{array}{l}\text { Percentage } \\
\text { Incorrect } \\
\text { Detection }\end{array}$ \\
\hline Comp. Haar T & $84 \%$ & $16 \%$ \\
\hline Haarlet Level 1 & $84 \%$ & $16 \%$ \\
\hline Haarlet Level 2 & $84.2 \%$ & $15.8 \%$ \\
\hline Haarlet Level 3 & $84.6 \%$ & $15.4 \%$ \\
\hline Haarlet Level 4 & $84.6 \%$ & $15.4 \%$ \\
\hline Haarlet Level 5 & $84.2 \%$ & $15.8 \%$ \\
\hline Haarlet Level 6 & $81.2 \%$ & $18.8 \%$ \\
\hline Haarlet Level 7 & $67.2 \%$ & $32.8 \%$ \\
\hline
\end{tabular}

In table $1 \& 2$ percentage correct and incorrect detection is shown. Here it can be seen that all levels nearly give the same detection rate except Haarlet-Level-7.

\section{CONCLUSION}

Recognition accuracy, robust method and computational costs are topics that must be taken into account when analyzing a face recognition method.

The FAR/FRR values show that Haarlets are outperforming Haar based image retrieval, proving that Haarlets has better discrimination capability. Also Haarlets of level-3 and Haarlets of level-4 is giving better performance than other Haarlets because higher level Haarlets are giving very coarse texture features while lower level Haarlets are giving too fine texture features losing discrimination capability, which are not really useful in face recognition and proper texture properties are carved by Haarlets level-4 at greatly reduced query execution time..

The proposed method (Haarlets-level-4) is also suitable for real time applications, during experimental tests the classification processing for a face was nearly 0.7 seconds.

\section{REFERENCES}

[1] Developed by Dr. Libor Spacek. Available Online at: http://cswww.essex.ac.uk/mv/otherprojects.html.

[2] H.B.Kekre, Sudeep D. Thepade, "Image Retrieval using Color-Texture Features Extracted from Haarlet Pyramid", ICGST International Journal on Graphics, Vision and Image Processing (GVIP), Volume 10, Issue I, Feb.2010, pp.9-18, Available online www.icgst.com/gvip/Volume10/Issue1/P1150938876.html

[3] H.B.Kekre, Sudeep D. Thepade, "Creating the Color Panoramic View using Medley of Grayscale and Color Partial Images ", WASET International Journal of Electrical, Computer and System Engineering (IJECSE), Volume 2, No. 3, Summer 2008. Available online at www.waset.org/ijecse/v2/v2-3-26.pdf.

[4] StianEdvardsen, "Classification of Images using color, CBIR Distance Measures and Genetic Programming", Ph.D. Thesis, Master of science in Informatics, Norwegian university of science and Technology, Department of computer and Information science, June 2006.

[5] H.B.Kekre, TanujaSarode, Sudeep D. Thepade, "DCT Applied to Row Mean and Column Vectors in Fingerprint Identification", In Proceedings of International Conference on Computer Networks and Security (ICCNS), 27-28 Sept. 2008, VIT, Pune.

[6] Zhibin Pan, Kotani K., Ohmi T., "Enhanced fast encoding method for vector quantization by finding an optimallyordered Walsh transform kernel", ICIP 2005, IEEE International Conference, Volume 1, pp I - 573-6, Sept. 2005.

[7] H.B.kekre, Sudeep D. Thepade, "Improving 'Color to Gray and Back' using Kekre's LUV Color Space”, IEEE International Advanced Computing Conference 2009 (IACC'09), Thapar University, Patiala, INDIA, 6-7 March 2009. Is uploaded and available online at IEEE Xplore. 
[8] H.B.Kekre, Sudeep D. Thepade, "Image Blending in Vista Creation using Kekre's LUV Color Space", SPIT-IEEE Colloquium and International Conference, Sardar Patel Institute of Technology, Andheri, Mumbai, 04-05 Feb 2008.

[9] H.B.Kekre, Sudeep D. Thepade, "Color Traits Transfer to Grayscale Images", In Proc.of IEEE First International Conference on Emerging Trends in Engg. \& Technology, (ICETET-08), G.H.Raisoni COE, Nagpur, INDIA. Uploaded on online IEEE Xplore.

[10] http://www.webopedia.com/TERM/F/false_rejection.html (last referred on 20/10/09)

[11] http://www.webopedia.com/TERM/F/false_acceptance.html( last referred on 20/10/09)

[12] K.-C. Liang and C. C. Kuo, "WaveGuide: A Joint WaveletBased Image Representation and Description System," IEEE Trans. on ImageProcessing, vol. 8, no. 11, pp.1619-1629, 1999

[13] Haar, Alfred, "ZurTheorie der orthogonalenFunktionensysteme". (German), MathematischeAnnalen, volume 69, No. 3, 1910, pp. 331371.

[14] Charles K. Chui, "An Introduction to Wavelets", Academic Press, 1992, San Diego, ISBN 0585470901.

[15] H.B.Kekre, Sudeep D. Thepade, AkshayMaloo "Face Recognition using Texture Feartures Extracted form Walshlet Pyramid", In Second International Joint Journal Conference in Computer, Electronics and Electrical, CEE 2010, November 2010 Issue.

\section{Author Biographies}

Dr. H. B. Kekre has received B.E. (Hons.) in Telecomm. Engineering. from Jabalpur University in 1958, M.Tech (Industrial Electronics) from IIT Bombay in 1960, M.S.Engg. (Electrical Engg.) from University of Ottawa in 1965 and Ph.D. (System Identification) from IIT Bombay in $1970 \mathrm{He}$ has worked as Faculty of Electrical Engg. and then HOD Computer Science and Engg. at IIT Bombay. For 13 years he was working as a professor and head in the Department of Computer Engg. atThadomalShahani Engineering.
College, Mumbai. Now he is Senior Professor at MPSTME, SVKM's NMIMSUniversity. He has guided $17 \mathrm{Ph} . \mathrm{Ds}$, more than 100 M.E./M.Tech and several B.E./B.Tech projects. His areas of interest are Digital Signal processing, Image Processing and Computer Networking. He has more than 300 papers in National / International Conferences and Journals to his credit. He was Senior Member of IEEE. Presently $\mathrm{He}$ is Fellow of IETE and Life Member of ISTE Recently nine students working under his guidance have received best paper awards. Currently 10 research scholars are pursuing Ph.D. program under his guidance.

Sudeep D. Thepade has Received B.E.(Computer) degree from North Maharashtra University with Distinction in 2003. M.E. in Computer Engineering from University of Mumbai in 2008 with Distinction, currently pursuing Ph.D. from SVKM's NMIMS, Mumbai. He has about than 08 years of experience in teaching and industry. He was Lecturer in Dept. of Information Technology at Thadomal Shahani Engineering College, Bandra(w), Mumbai for nearly 04 years. Currently working as Associate Professor in Computer Engineering at Mukesh Patel School of Technology Management and Engineering, SVKM's NMIMS University, Vile Parle(w), Mumbai, INDIA. He is member of International Association of Engineers (IAENG) and International Association of Computer Science and Information Technology (IACSIT), Singapore. His areas of interest are Image Processing and Computer Networks. He has about 90 papers in National/International Conferences/Journals to his credit with a Best Paper Award at International Conference SSPCCIN-2008, Second Best Paper Award at ThinkQuest-2009 National Level paper presentation competition for faculty, second award at research project competition 'MANSHODHAN-2010' and Best Paper Award at Springer International Conference ICCCT-2010.

AkshayMaloois currently pursuing B.Tech. (CS) from MPSTME, NMIMS University, Mumbai. His areas of interest are Artificial intelligence, Image Processing, Computer Networks and Security. He has 13 papers in International Journals to his credit. 